\title{
Genetic and Clinical Features of P450 Oxidoreductase Deficiency
}

\author{
Rachel R. Scott ${ }^{\mathrm{a}}$ Walter L. Miller ${ }^{\mathrm{b}}$ \\ a Division of Endocrinology, Department of Paediatrics, IWK Health Centre, Dalhousie University, Halifax, N.S., \\ Canada; ${ }^{b}$ Division of Endocrinology, Department of Pediatrics, University of California, San Francisco, Calif., USA
}

\section{Key Words}

Adrenal $\cdot$ steroidogenesis $\cdot$ Craniosynostosis •

Antley-Bixler syndrome • Ambiguous genitalia

FGFR2 mutations · Adrenal steroidogenesis

\begin{abstract}
P450 oxidoreductase (POR) deficiency is an autosomal recessive disorder of steroidogenesis with multiple clinical manifestations. POR is the electron donor for all microsomal P450 enzymes, including the three steroidogenic enzymes P450c17 (17 $\alpha$-hydroxylase/17,20-lyase), P450c21 (21-hydroxylase), and P450aro (aromatase). Since the first description of POR mutations in 2004, about 50 patients have been reported. Serum steroid profiles indicate partial deficiencies in 21 -hydroxylase, $17 \alpha$-hydroxylase and 17,20-lyase. The 17-OH progesterone levels are elevated, as in 21-hydroxylase deficiency, while androgen levels are low; cortisol may be normal but is poorly responsive to adrenocorticotropic hormone. Most patients also have associated skeletal malformations (craniosynostosis, radio-ulnar synostosis, midface hypoplasia, bowed femora) termed Antley-Bixler syndrome. Antley-Bixler syndrome with normal steroidogenesis is caused by autosomal dominant gain-of-function mutations in fibroblast growth factor receptor 2. Males with POR deficiency are often undervirilized, while females can be virilized. The prognosis for patients with POR deficiency appears to depend on the severity of the bony malformations and
\end{abstract}

\section{KARGER}

Fax +41613061234

E-Mail karger@karger.ch

www.karger.com
(C) 2008 S. Karger AG, Basel their timely treatment. The potential impact of POR mutations on drug metabolism by other hepatic P450 enzymes requires further investigation. Given the varied physical and biochemical phenotype of POR deficiency and the risk of adrenal insufficiency, clinicians should be alert to this potential diagnosis.

Copyright $\odot 2008$ S. Karger AG, Basel

\section{Introduction}

Most forms of congenital adrenal hyperplasia (CAH) are caused by mutations in genes encoding steroidogenic enzymes; mutant genes result in diminished or absent enzymatic activity, so that the clinical signs and symptoms are caused by accumulation of some steroidal precursors and/or decreased production of the principal steroidal end products. Two forms of CAH are not caused by mutations in steroidogenic enzymes: congenital lipoid adrenal hyperplasia, caused by mutations in the steroidogenic acute regulatory protein [1], and the recently described P450 oxidoreductase (POR) deficiency [2-5]. POR deficiency is the most complex of the various forms of CAH, because it affects the activity of several steroidogenic enzymes, yields a complex and variable pattern of abnormal steroid hormones, has a broad spectrum of clinical severity, and affects a number of 'non-endocrine' systems, including skeletal development and drug me-

\footnotetext{
Dr. Rachel Scott

IWK Health Centre

5850/5980 University Avenue

Halifax, N.S. B3K 6R8 (Canada)

Tel. +1 902470 8707, Fax +1 902470 7264, E-Mail rrscott@dal.ca
} 


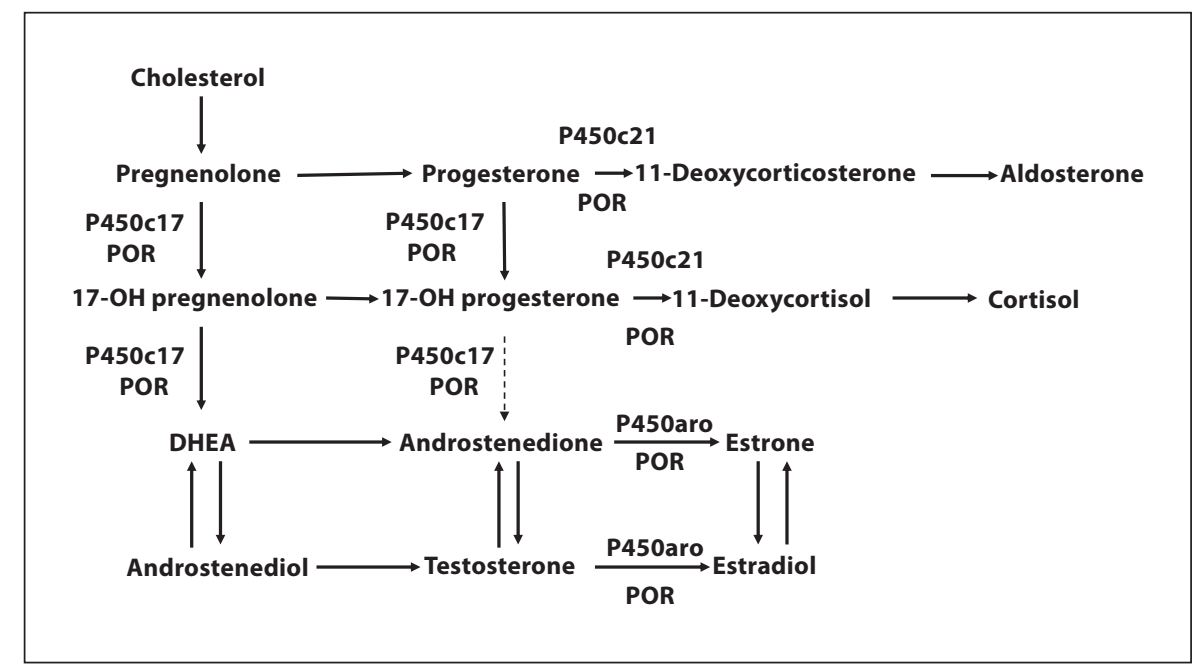

Fig. 1. Simplified steroid biosynthetic pathway indicating the steps where POR acts as a cofactor. POR supports the activities of P450c17, P450c21, and P450aro. Because the 17,20-lyase activity of human $\mathrm{P} 450 \mathrm{cl} 17$ does not effectively convert $17-\mathrm{OH}$ progesterone (17-OHP) to androstenedione, 17-OHP accumulates when the 21-hydroxylase activity is impaired. The 17,20-lyase activity of $\mathrm{P} 450 \mathrm{c} 17$ is more sensitive to perturbations in electron transfer than is its $17 \alpha$-hydroxylase activity, so that the synthesis of DHEA, androstenedione, testosterone, and estradiol is more severely affected. Thus, the typical patient with POR deficiency will have a mildly elevated 17-OHP and low 19-carbon steroids. The combined partial impairment of $17 \alpha$-hydroxylase activity and 21-hydroxylase activity may also compromise cortisol synthesis. tabolism. However, POR deficiency appears to be fairly common, with about 50 cases being described in the 3 years following the first report, hence endocrinologists, geneticists, and others need to become familiar with this newly characterized disorder.

\section{P450 Enzymes and POR}

Cytochrome P450 enzymes, named for their characteristic spectral shift at $450 \mathrm{~nm}$, perform a wide variety of oxidative reactions. The human genome encodes 57 distinct P450 enzymes; 7 of these are type I, found in mitochondria, and 50 are type II, found in the endoplasmic reticulum. Type I P450 enzymes receive electrons from NADPH via an electron transfer chain consisting of two proteins, ferredoxin and ferredoxin reductase, whereas type II P450 enzymes receive electrons from NADPH via a single redox partner, POR [6]. Three of the 50 type II P450 enzymes are involved in steroidogenesis: P450c21, the adrenal 21-hydroxylase; P450c17, which catalyzes both 17,20-lyase and 17 $\alpha$-hydroxylase activities, and P450aro, which aromatizes androgens to estrogens (fig. 1).

P450 Oxidoreductase Deficiency
POR is an $82-\mathrm{kDa}$ flavoprotein associated with the endoplasmic reticulum. Human POR contains 680 amino acids, whereas POR from rodents and most other species contains 677 amino acids. The human gene was identified on chromosome 7q11.2 as part of the Human Genome Project. The gene consists of 15 protein-coding exons spanning $32 \mathrm{~kb}$ (named exons 1-15), but it also has a non-coding exon (termed exon $1 \mathrm{U}$ ) located $38 \mathrm{~kb}$ upstream [7].

Unlike ferredoxin reductase, which has only one flavin adenine dinucleotide (FAD) molecule to accept electrons from NADPH, POR has a molecule of FAD and one of flavin mononucleotide (FMN) on two distinct domains (fig. 2). This enables POR to donate electrons directly to the P450 enzyme without an intermediate such as ferredoxin. A flexible hinge region separates the two domains: once FAD receives an electron from NADPH, the hinge flexes and allows the FAD domain to align with the FMN domain and pass along its electron. Further flexion then permits the FMN domain to associate with the redox-partner-binding site of the P450 enzyme. Cytochrome $b_{5}$ has an allosteric effect that promotes the interaction of POR with P450c17 and some of the hepatic P450 enzymes [8-10] and can sometimes function as an alternative donor of the second electron in the POR cata-

Horm Res 2008;69:266-275 
lytic cycle [11]. The relative abundance of POR in relation to the P450 can influence the enzyme activity: addition of POR increases the 17,20-lyase reaction over the $17 \alpha$ hydroxylase activity of P450c17 [12, 13].

\section{POR Deficiency}

In 1985, Peterson et al. [14] reported a 46,XY undervirilized infant with low levels of 19-carbon steroids but elevated 17-OHP and 17-OH pregnenolone levels, suggesting combined deficiencies of $17 \alpha$-hydroxylase, 17,20 lyase, and 21-hydroxylase. Other similar cases were subsequently reported [15-20]; many of these patients had skeletal malformations consistent with Antley-Bixler syndrome (ABS). POR deficiency was suggested early on as the most logical explanation for this steroid profile [21], but following reports that POR ablation in the mouse confers embryonic lethality, the hypothesis was thought unlikely [22,23]. The lethality appears to be due to extrahepatic POR deficiency, since a liver-specific POR knockout mouse has a severely impaired drug metabolism but normal development and reproductive capacity [24, 25]. Despite the mouse data, Flück et al. [2] found POR mutations in 3 children with ABS and in 1 woman with primary amenorrhoea and polycystic ovaries without skeletal malformations. Other investigators [3, 4, 7, 26-29] have subsequently found POR mutations in patients with the ABS phenotype plus abnormal genitalia and/or disordered steroidogenesis as well as in some patients without bony anomalies. Approximately 20 mutations in 50 patients have been described to date (table 1).

\section{Antley-Bixler Syndrome}

ABS is a skeletal malformation syndrome first described in 1975 [30] that includes craniosynostosis, midface hypoplasia, choanal atresia or stenosis, radiohumeral and/or radio-ulnar synostosis, femoral bowing and fractures, and joint contractures [30-33]. Diagnostic criteria for ABS are not definitively established, but craniosynostosis and elbow synostosis are minimum requirements [34-36]. In a review of 22 cases of ABS, Bottero et al. [33] found that $>90 \%$ of the cases had craniosynostosis, midface hypoplasia, radiohumeral or radio-ulnar synostosis, joint contractures, femoral bowing, dysplastic ears, and a 'pear-shaped' nose.

The genetics of ABS was initially controversial: reports of affected siblings $[37,38]$ and parental consan-

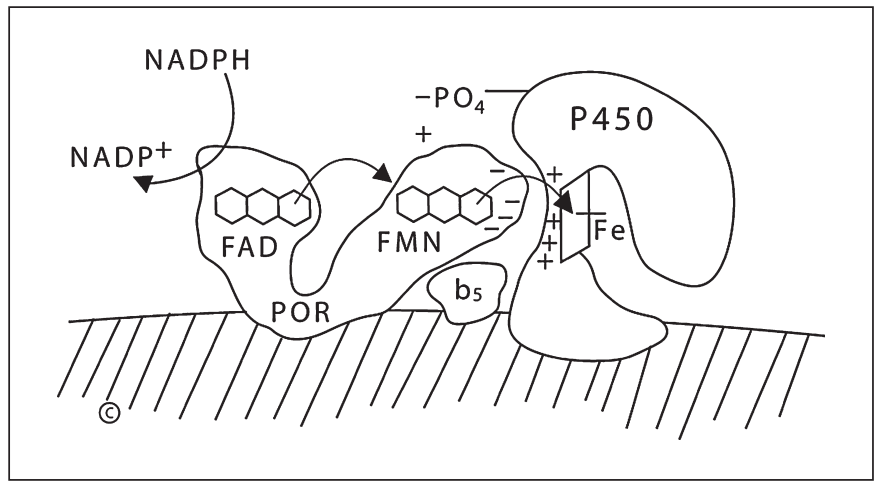

Fig. 2. Diagram demonstrating the role of $\mathrm{P} 450$ oxidoreductase (POR) in electron transfer by microsomal (type II) P450 enzymes. NADPH interacts with POR, bound to the endoplasmic reticulum, and gives up a pair of electrons $\left(\mathrm{e}^{-}\right)$which are received by the flavin adenine dinucleotide (FAD) moiety. Electron receipt elicits a conformational change in the flexible hinge region of POR, so that the electrons pass from the FAD domain to the flavin mononucleotide (FMN) domain. Following another conformational change that returns the protein to its original orientation, the FMN domain of POR interacts with the redox partner binding site of the P450 enzyme. The interaction of POR and the P450 is co-ordinated by negatively charged acidic residues on the surface of the FMN domain of POR and by positively charged basic residues in the redox partner binding site of the P450. In the case of human $\mathrm{P} 450 \mathrm{c} 17$, this interaction is facilitated by the allosteric action of cytochrome $b_{5}$.

guinity [39] suggested autosomal recessive inheritance, but autosomal dominant fibroblast growth factor receptor 2 (FGFR2) mutations have been found in a number of cases $[19,34,36,40,41]$. Fibroblast growth factors (FGFs) are mitogens involved in bone growth and development [42]. FGFs can bind four different tyrosine kinase cell surface receptors (FGFRs). Dominant gain-of-function mutations in FGFRs (primarily FGFR2) cause a number of phenotypically diverse craniosynostosis syndromes, including Pfeiffer, Apert, Jackson-Weiss, and Crouzon syndromes [43-47]. The same mutation can cause two different clinical syndromes, supporting the concept that these syndromes represent phenotypic variations of the same genetic disorder [45-47].

Unlike the other craniosynostosis syndromes, ABS patients have a high incidence of genital anomalies that ranges from 31 to $64 \%$, including hypoplastic labia majora, clitoromegaly, male genital hypoplasia, and cryptorchidism [19, 32, 33].

It was observed that while cases of ABS with FGFR2 mutations had normal genitalia [34, 36, 40, 41], reported 
Table 1. Reported patients with P450 oxidoreductase (POR) deficiency

\begin{tabular}{|c|c|c|c|c|c|c|}
\hline \multirow[t]{2}{*}{ Patients } & \multirow{2}{*}{$\begin{array}{l}\text { Chromosomal } \\
\text { sex } \\
46, \mathrm{XX} / 46, \mathrm{XY}\end{array}$} & \multirow{2}{*}{$\begin{array}{l}\text { POR } \\
\text { mutations }\end{array}$} & \multicolumn{3}{|c|}{ Phenotype } & \multirow{2}{*}{$\begin{array}{l}\text { Refer- } \\
\text { ences }\end{array}$} \\
\hline & & & $\begin{array}{l}\text { ABS } \\
\text { features }\end{array}$ & $\begin{array}{l}\text { Abnormal } \\
\text { genitalia }\end{array}$ & $\begin{array}{l}\text { Abnormal } \\
\text { steroids }\end{array}$ & \\
\hline 4 & $2 / 2$ & $7 / 8^{\mathrm{a}}$ & 3 & 3 & 4 & 2 \\
\hline 3 & $2 / 1$ & $6 / 6$ & 1 & 2 & 3 & 3 \\
\hline 2 & $1 / 1$ & $4 / 4$ & 2 & 1 & 2 & 4 \\
\hline $19(32)^{\mathrm{b}}$ & $6 / 10^{c}$ & $34 / 38^{a}$ & $19(32)^{b}$ & $12^{\mathrm{c}}$ & $10^{c}$ & 26 \\
\hline 10 & $6 / 4$ & $19 / 20^{\mathrm{a}}$ & 9 & 9 & 10 & 27 \\
\hline 3 & $2 / 1$ & $6 / 6$ & 0 & 2 & 3 & 28 \\
\hline 7 & $2 / 5$ & $14 / 14$ & 5 & 2 & 7 & 29 \\
\hline 1 & $1 / 0$ & $1 / 2^{\mathrm{a}}$ & 1 & 1 & 1 & 7 \\
\hline 49 & $22 / 24$ & $91 / 98$ & $40 / 49$ & $32 / 49$ & $40 / 49$ & \\
\hline \multicolumn{7}{|c|}{ ABS $=$ Antley-Bixler syndrome } \\
\hline
\end{tabular}

cases of ABS with apparent autosomal recessive inheritance had genital abnormalities [19, 38, 39, 43]. FGFR2 mutations were found in 7 of $16 \mathrm{ABS}$ patients, but FGFR2 mutations and genital abnormalities segregated completely [19]. Since genital abnormalities are not a feature of any of the other craniosynostosis syndromes caused by FGFR2 mutations, Reardon et al. [19] proposed that ABS with genital and/or steroid abnormalities was likely due to 'digenic inheritance', involving both a factor related to FGFR2 and some other factor involved in genital development.

A phenotype similar to ABS with genital anomalies has been described in children exposed to fluconazole in utero [48-50]. Fluconazole is an inhibitor of lanosterol $14 \alpha$-demethylase (CYP51), a type II P450 enzyme that converts lanosterol to ergosterol. Speculating that a defect in cholesterol biosynthesis might cause ABS [49], Kelley et al. [20] showed that lymphoblast cells from a patient with $\mathrm{ABS}$ and genital abnormalities had higher levels of lanosterol than normal cells or cells from a patient with ABS and an FGFR2 mutation. Despite this apparent defect in CYP51 function, sequencing of the CYP51 gene revealed no mutation. The patient of Kelley and colleagues with ABS and genital anomalies was one of those described in the original report of POR mutations; he is homozygous for the A287P mutation which explains the decreased CYP51 activity [2].

P450 Oxidoreductase Deficiency

\section{POR Deficiency - Genetics and Biochemistry}

About 26 different POR mutations have been identified to date, including 14 missense mutations, eight frameshift mutations, one deletion, and three splicing errors [2-4, 26, 27, 29]. Mutations have been found in all four POR domains. Most of the missense mutations are in the central electron transfer domain $[2,3,26]$. The most common mutation in people of European descent is A287P, while $\mathrm{R} 457 \mathrm{H}$ is often found in Japan $[4,27,29]$. Interestingly, $12 \%$ of the reported patients have only one identified mutation $[2,7,26,27]$. These patients are clinically indistinguishable from those with two mutations, pointing toward possible mutations in as yet unidentified regulatory regions [7]. Patients with the same mutations, even siblings, can be phenotypically different [3, 27, 28, 51]. However, patients with POR mutations always have hormonal profiles compatible with partial deficiencies of 21-hydroxylase and $17 \alpha$-hydroxylase/ 17,20-lyase.

Analysis of the enzymatic capacity of different POR mutants allows for correlations between genotype and phenotype. The classic in vitro assay of POR function is reduction of cytochrome $c$, using a soluble form of POR, which is not a physiological assay for membrane-bound POR and does not always correlate well with the phenotype for a given mutation $[2,3,26]$. A more physiological assay, using a system of genetically modified yeast and

Horm Res 2008;69:266-275 
Fig. 3. Schematic of the POR gene structure, showing all exons, introns, and known sequence variations. The exons are the numbered boxes. Exon $1 \mathrm{U}$ is the untranslated exon approximately $38 \mathrm{~kb}$ upstream from the rest of the gene. The distances between exons $1 \mathrm{U}, 1,2$, and 3 are not to scale. All sequence variations are named in accordance with the recommendations of Antonarakis [61].

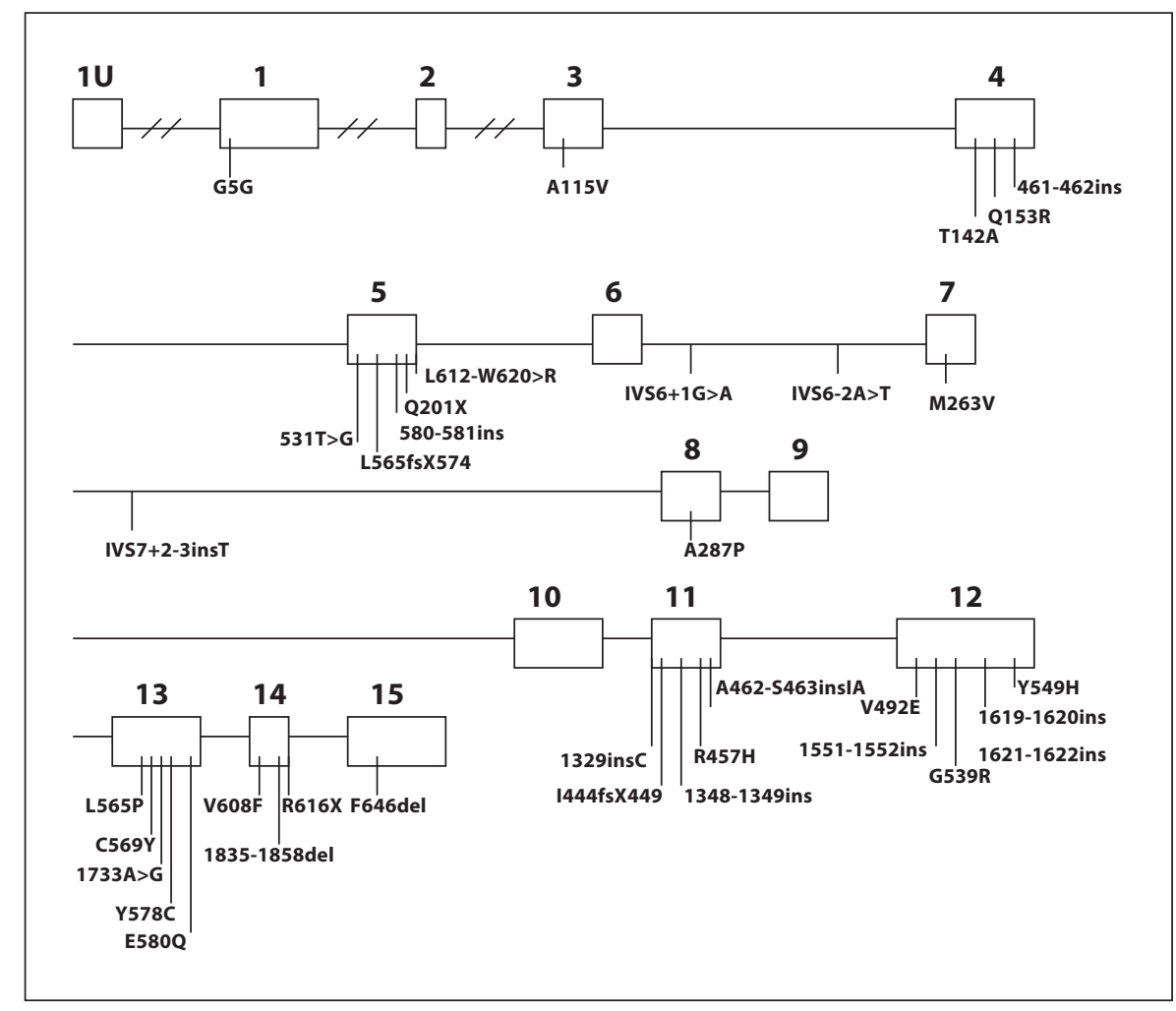

bacteria expressing human P450c17 and POR mutants, measures the ability of POR to support catalysis by P450c17 and consistently correlates with the phenotype $[2,26]$.

\section{POR Deficiency - Endocrinology}

Unlike other genetic defects of steroidogenesis, POR deficiency affects multiple enzymes that generally retain partial activity, making the steroid profiles in patients with POR deficiency variable. The activities of adrenal 21-hydroxylase (P450c21) and 17 $\alpha$-hydroxylase/17,20-lyase (P450c17) are impaired. The impairment of P450c21 results in 17-hydroxyprogesterone (17-OHP) that is hyperresponsive to adrenocorticotropic hormone (ACTH) stimulation and elevated 21-deoxycortisol. DHEA (dehydroepiandrosterone), DHEAS (DHEA sulfate), and androstenedione are low to normal because of impaired 17,20-lyase activity. This hormonal pattern, with elevated 17-OHP levels, indicates that the 21-hydroxylation by $\mathrm{P} 450 \mathrm{c} 21$ is inhibited to a greater degree than the $17 \alpha$-hydroxylation by $\mathrm{P} 450 \mathrm{c} 17$, but the effects of POR mutations on $\mathrm{P} 450 \mathrm{c} 21$ have not yet been studied in vitro. The 11-de- oxycortisol level is low. Basal, unstimulated values for cortisol are usually normal or nearly normal, but do not respond normally to stimulation with $\mathrm{ACTH}$, indicating chronically compensated adrenal insufficiency. Correspondingly, the ACTH values may be high. Table 2 summarizes the plasma steroid profiles of reported patients with POR deficiency. Consistent with the inadequate cortisol response to ACTH stimulation, 5 out of the 49 reported cases had clinical signs of adrenal insufficiency $[2,4,27]$, and an additional patient died of sepsis while on glucocorticoid and mineralocorticoid replacement therapy [26]. Thus assessment of adrenal function with ACTH stimulation testing and, if indicated, physiological glucocorticoid replacement are appropriate in POR deficiency.

\section{POR Deficiency - Phenotype}

The bony malformations of POR deficiency are indistinguishable from those of ABS caused by FGFR2 mutations and include midface hypoplasia, craniosynostosis, pear-shaped nose, choanal stenosis or atresia, low-set ears, and radiohumeral or radio-ulnar synostosis [26]. 
Table 2. Plasma steroid hormone profiles of reported patients with $\mathrm{P} 450$ oxidoreductase (POR) deficiency

\begin{tabular}{|c|c|c|c|c|c|c|c|c|c|}
\hline \multirow{2}{*}{$\begin{array}{l}\text { Study and } \\
\text { patient number }\end{array}$} & \multicolumn{9}{|c|}{ Steroid hormone levels } \\
\hline & $\begin{array}{l}\text { cortisol } \\
\text { basal }\end{array}$ & $\begin{array}{l}\text { cortisol } \\
\text { stimulated }\end{array}$ & $\begin{array}{l}17-\mathrm{OHP} \\
\text { basal }\end{array}$ & $\begin{array}{l}17-\mathrm{OHP} \\
\text { stimulated }\end{array}$ & DOC & DHEA & DHEAS & A & $\mathrm{T}$ \\
\hline \multicolumn{10}{|c|}{ Flück et al. (2004) [2] } \\
\hline 1 & $\downarrow$ & $\downarrow$ & $\uparrow$ & & & & & & $\leftrightarrow$ \\
\hline 2 & $\leftrightarrow$ & & $\uparrow$ & $\uparrow$ & & $\downarrow$ & & $\downarrow$ & \\
\hline 3 & & & & & & & & & \\
\hline 4 & $\leftrightarrow$ & $\downarrow$ & $\uparrow$ & $\uparrow$ & $\uparrow$ & & & $\downarrow$ & $\leftrightarrow$ \\
\hline \multicolumn{10}{|c|}{ Arlt et al. (2004) [3] } \\
\hline 1 & & & & & & & & & $\leftrightarrow$ \\
\hline 2 & & & $\uparrow$ & & & & & & \\
\hline 3 & & & $\uparrow$ & & & & $\leftrightarrow$ & $\leftrightarrow$ & $\leftrightarrow$ \\
\hline \multicolumn{10}{|c|}{ Huang et al. (2005) [26] } \\
\hline 1 & $\downarrow$ & $\leftrightarrow$ & & & & & $\leftrightarrow$ & $\leftrightarrow$ & $\leftrightarrow$ \\
\hline 2 & $\leftrightarrow$ & & $\uparrow$ & $\uparrow$ & & $\downarrow$ & & $\downarrow$ & \\
\hline 3 & & & $\uparrow$ & & & & & & \\
\hline 4 & $\leftrightarrow$ & & $\leftrightarrow$ & & & $\leftrightarrow$ & $\leftrightarrow$ & $\leftrightarrow$ & \\
\hline 16 & $\leftrightarrow$ & $\downarrow$ & $\uparrow$ & & & & & & \\
\hline 31 & $\leftrightarrow$ & & $\uparrow$ & & & & $\leftrightarrow$ & $\leftrightarrow$ & $\leftrightarrow$ \\
\hline 32 & $\leftrightarrow$ & $\downarrow$ & $\uparrow$ & $\uparrow$ & & & $\downarrow$ & $\downarrow$ & $\downarrow$ \\
\hline
\end{tabular}

\begin{tabular}{|c|c|c|c|c|c|c|c|c|}
\hline \multicolumn{9}{|c|}{ Fukami et al. (2005) [27] } \\
\hline 1 & $\leftrightarrow$ & $\downarrow$ & $\uparrow$ & $\uparrow$ & $\uparrow$ & $\downarrow$ & $\downarrow$ & $\downarrow$ \\
\hline 2 & $\leftrightarrow$ & & $\uparrow$ & & $\uparrow$ & $\leftrightarrow$ & $\leftrightarrow$ & $\leftrightarrow$ \\
\hline 3 & $\leftrightarrow$ & $\downarrow$ & $\uparrow$ & $\uparrow$ & $\uparrow$ & $\downarrow$ & $\leftrightarrow$ & $\uparrow$ \\
\hline 4 & $\leftrightarrow$ & $\downarrow$ & $\uparrow$ & $\uparrow$ & & & & $\leftrightarrow$ \\
\hline 5 & $\leftrightarrow$ & $\downarrow$ & $\uparrow$ & $\uparrow$ & $\uparrow$ & $\leftrightarrow$ & $\downarrow$ & $\downarrow$ \\
\hline 6 & $\leftrightarrow$ & $\downarrow$ & $\uparrow$ & $\uparrow$ & $\uparrow$ & $\downarrow$ & $\leftrightarrow$ & $\leftrightarrow$ \\
\hline 7 & $\leftrightarrow$ & $\downarrow$ & $\uparrow$ & $\uparrow$ & $\leftrightarrow$ & $\leftrightarrow$ & $\downarrow$ & $\leftrightarrow$ \\
\hline 8 & $\leftrightarrow$ & $\downarrow$ & $\uparrow$ & $\uparrow$ & & & & $\leftrightarrow$ \\
\hline 9 & $\leftrightarrow$ & $\downarrow$ & $\uparrow$ & $\uparrow$ & $\leftrightarrow$ & $\leftrightarrow$ & $\uparrow$ & $\leftrightarrow$ \\
\hline 10 & $\uparrow$ & $\leftrightarrow$ & $\uparrow$ & & $\uparrow$ & $\leftrightarrow$ & $\uparrow$ & $\uparrow$ \\
\hline
\end{tabular}

Fukami et al. (2006) [28]

\begin{tabular}{ccccccccc}
1 & $\leftrightarrow$ & $\downarrow$ & $\uparrow$ & $\uparrow$ & $\uparrow$ & & & \\
2 & $\leftrightarrow$ & $\downarrow$ & $\uparrow$ & $\uparrow$ & $\leftrightarrow$ & $\leftrightarrow$ & $\leftrightarrow$ \\
3 & $\leftrightarrow$ & $\downarrow$ & $\uparrow$ & $\uparrow$ & $\leftrightarrow$ & $\leftrightarrow$ & $\leftrightarrow$ & $\leftrightarrow$ \\
\hline
\end{tabular}

Scott et al. (2007) [7]

This table includes only reported patients for whom there are some published plasma hormone data. Numbers in bold denote females; $\leftrightarrow$ means the value was in the normal range; $\downarrow$ means the value was below the normal range; $\uparrow$ means the value was above the normal range. Blank cells indicate that this value was not reported.

Stimulated = Value after stimulation with $\mathrm{ACTH} ; 17-\mathrm{OHP}=17-\mathrm{OH}$ progesterone DOC $=$ deoxycorticosterone; $\mathrm{DHEA}=$ dehydroepiandrosterone; DHEAS = dehydroepiandrosterone sulfate; $\mathrm{A}$ = androstenedione; $\mathrm{T}=$ testosterone.

Femoral bowing, femoral fractures, and arachnodactyly are also frequently observed. Although the pathogenesis of these bone malformations is unknown, there are several elements pointing to connections between cholester- ol biosynthesis and skeletal development: First, the known human disorders of cholesterol biosynthesis are all associated with skeletal abnormalities. The best-known of these is Smith-Lemli-Opitz syndrome, caused by muta- 
tions in the gene encoding 7-dehydrocholesterol reductase [52]. Second, cholesterol is required for normal activity and signal transduction of the hedgehog proteins which are crucial for the regulation of growth and morphogenesis of embryonic structures. Third, a bony phenotype similar to ABS is seen in infants with in utero exposure to fluconazole [48-50]. Lanosterol $14 \alpha$-demethylase, a cytochrome P450 enzyme involved in cholesterol biosynthesis and which requires POR as an electron donor, is inhibited by fluconazole and has decreased activity in POR deficiency $[2,20]$. These data suggest that abnormalities in cholesterol biosynthesis, caused by POR deficiency, could be responsible for the skeletal abnormalities seen in many patients with this disease.

Unlike the common single enzyme defects in adrenal steroidogenesis, which cause either virilization in girls or undervirilization in boys, POR deficiency can cause abnormal genital development in both sexes. Boys are often undervirilized, because decreased 17,20-lyase activity prevents the formation of 19-carbon androgen precursors. The 17,20-lyase activity of P450c17 is more sensitive than the $17 \alpha$-hydroxylase activity to a deficiency in POR $[12,53,54]$. In contrast, girls with POR deficiency are frequently virilized, but with no postnatal progression, unlike girls with untreated 21-hydroxylase deficiency [55]. There are two hypotheses as to the origin of this virilization, although neither has been definitively proven $[3,51$, 56]. POR deficiency impairs the activity of P450aro (aromatase) which converts fetal 19-carbon androgen precursors to estrogens. Placental aromatase deficiency leads to maternal virilization and low maternal estriol and estrone [57] levels, both of which have been described in POR deficiency $[2-4,27-29,51]$. However, the main fetoplacental substrates for P450aro, $16 \alpha \mathrm{OH}$-DHEA and androstenedione, are low in POR deficiency, and the usual urinary metabolites seen in placental aromatase deficiency are not always found in POR deficiency [3]. An alternate hypothesis for the source of androgen excess in girls with POR deficiency is the 'backdoor pathway' to androgen production $[29,51]$. In this pathway, 21-carbon steroid precursors are $5 \alpha$-reduced and ultimately converted to dihydrotestosterone, bypassing the conventional precursors androstenedione and testosterone [56]. This is the main mechanism of androgen production in some animal species [58]; since human steroidogenic tissues contain the necessary enzymes [56], it has been proposed that the elevated levels of 17-OHP in POR deficiency provide substrate for this pathway $[3,29,51,56]$. Evidence supporting this theory includes: a urinary metabolite of this pathway has been detected in the mother of a POR- deficient fetus [51], urinary analysis of 22 patients with POR deficiency showed decreased products of the conventional androgen biosynthetic pathways (etiocholanolone and 11-OH androsterone) but increased androsterone which can be derived from the backdoor pathway [29], and $\mathrm{P} 450 \mathrm{c} 17$ has greater affinity for the $5 \alpha$-reduced form of 21-carbon steroids than for 17-OHP and 17-OH pregnenolone [59]. The exact role of this pathway in human androgen production, especially in the setting of disordered steroidogenesis, remains unclear.

\section{POR Deficiency - Diagnosis and Treatment}

Because of the variability in phenotype and steroid hormone profile in POR deficiency, the diagnosis is not as straightforward as in other causes of CAH. DNA sequencing has assumed an important role in the diagnosis of this disorder. Insufficient cortisol production, especially during periods of stress, is always possible, and all patients with POR deficiency should undergo an ACTH stimulation test and receive hydrocortisone replacement if indicated. Aldosterone deficiency with salt wasting has not yet been described in this disorder but is theoretically possible, because 21-hydroxylase activity requires POR.

In pregnancy, estriol is the product of aromatization of fetal androgen precursors (DHEAS), and it is measured as part of screening for trisomy 21 and open neural tube defects. In the absence of fetal anomalies on ultrasound, low estriol is caused by adrenal steroid biosynthetic defects that cause impaired DHEAS production (steroid sulfatase deficiency, 17 $\alpha$-hydroxylase deficiency, steroidogenic acute regulatory protein deficiency), adrenal hypoplasia (hypopituitarism, isolated ACTH deficiency), Smith-Lemli-Opitz syndrome, and placental aromatase deficiency. POR deficiency, because of its effect on the 17,20-lyase activity of P450c17, is known to cause low maternal estriol levels in pregnancy [51] and must also be considered in this differential diagnosis when evaluating low estriol levels in a pregnant woman.

The bony anomalies of POR deficiency require orthopaedic management. Earlier reports on ABS described a high mortality rate (50-85\%), generally attributed to upper airway obstruction [33,60]. Bottero et al. [33] observed that most of the patients who died in infancy had choanal obstruction $(75 \%)$ and that early surgical correction of airway problems led to improved outcomes. Of the 50 reported patients with POR deficiency, only 3 died in 
infancy $[2-4,7,26-29]$. The reason for the lower death rate in patients with confirmed POR deficiency is unknown: it may reflect a less severe disease than in patients with FGFR2 mutations, better care in more recently diagnosed patients, better care by endocrinologists, or ascertainment bias, as it is difficult to get DNA for research from deceased patients. Nevertheless, the morbidity and mortality associated with bony abnormalities require prompt intervention.

Bony abnormalities may be absent or subtle in POR deficiency, presenting a diagnostic challenge for the clinician. The reported phenotypic spectrum of patients with POR mutations and no bony problems includes completely asymptomatic patients detected by neonatal screening for 21-hydroxylase deficiency, asymptomatic patients whose mothers were virilized during pregnancy, a virilized female infant, and an adult woman with primary amenorrhoea and cystic ovaries [2, 3, 28, 29]. In all of these cases, steroid hormone analysis led to the suspicion of POR deficiency which was then confirmed by mutation analysis. Given the broad range of clinical manifestations already documented in POR deficiency, it is reasonable to suspect that there are a large number of undiagnosed patients with mild or normal phenotypes. POR deficiency must be considered in the evaluation of any child with sexual ambiguity or a history of maternal virilization during pregnancy. Mutation analysis is indicated in patients with compatible steroid hormone profiles.

Another potentially important clinical consideration is the effect of POR mutations on non-steroidogenic P450 enzymes. Most drugs are metabolized by a small number of hepatic P450 enzymes that require the activity of POR. Sequence variations in hepatic P450 enzymes are known to cause variability in drug metabolism between individuals, but the impact of variations in POR on these hepatic enzymes has not been investigated. The liver-specific POR knockout mouse has a severely impaired hepatic drug metabolism [24]. The available clinical reports of POR deficiency do not permit a clinical assessment of drug metabolism in POR-deficient patients.

\section{Conclusions}

Unlike the other causes of CAH, POR deficiency has consequences beyond abnormal steroidogenesis: skeletal development is often abnormal, enzymes involved in cholesterol biosynthesis are affected, and there is potential for altered drug metabolism. Most reported mortality is related to the skeletal malformations, thus prompt and expert management of patients with upper airway obstruction is essential. Patients are also at risk of adrenal insufficiency and should undergo ACTH stimulation testing, especially before surgery to correct bony abnormalities. Clinicians should also remain alert to any clinical evidence of abnormal drug metabolism in patients with POR mutations.

\section{Acknowledgment}

This work was supported by National Institutes of Health grant GM 073020 (to W.L.M.).

\section{References}

1 Miller WL: Congenital lipoid adrenal hyperplasia: the human gene knockout for the steroidogenic acute regulatory protein. J Mol Endocrinol 1997;19:227-240.

-2 Flück CE, Tajima T, Pandey AV, Arlt W, Okuhara K, Verge CF, Jabs EW, Mendonça BB, Fujieda K, Miller WL: Mutant P450 oxidoreductase causes disordered steroidogenesis with and without Antley-Bixler syndrome. Nat Genet 2004;36:228-230.

$\checkmark 3$ Arlt W, Walker EA, Draper N, Ivison HE, Ride JP, Hammer F, Chalder SM, BoruckaMankiewicz M, Hauffa BP, Malunowicz EM, Stewart PM, Shackleton CH: Congenital adrenal hyperplasia caused by mutant $\mathrm{P} 450$ oxidoreductase and human androgen synthesis: analytical study. Lancet 2004;363: 2128-2135.
4 Adachi M, Tachibana K, Asakura Y, Yamamoto T, Hanaki K, Oka A: Compound heterozygous mutations of cytochrome P450 oxidoreductase gene (POR) in two patients with Antley-Bixler syndrome. Am J Med Genet A 2004;128:333-339.

5 Miller WL: P450 oxidoreductase deficiency: a new disorder of steroidogenesis with multiple clinical manifestations. Trends Endocrinol Metab 2004;15:311-315.

6 Miller WL: Minireview: regulation of steroidogenesis by electron transfer. Endocrinology 2005; 146:2544-2550.

7 Scott RR, Gomes LG, Huang N, Van Vliet G, Miller WL: Apparent manifesting heterozygosity in P450 oxidoreductase deficiency and its effect on coexisting 21-hydroxylase deficiency. J Clin Endocrinol Metab 2007;92: 2318-2322.
8 Yamazaki H, Johnson WW, Ueng YF, Shimada T, Guengerich FP: Lack of electron transfer from cytochrome $b_{5}$ in stimulation of catalytic activities of cytochrome P450 3A4. Characterization of a reconstituted cytochrome P450 3A4/NADPH-cytochrome $\mathrm{P} 450$ reductase system and studies with apocytochrome $b_{5}$. J Biol Chem 1996;271:2743827444.

>9 Auchus RJ, Lee TC, Miller WL: Cytochrome $b_{5}$ augments the 17,20-lyase activity of human P450c17 without direct electron transfer. J Biol Chem 1998;273:3158-3165.

10 Geller DH, Auchus RJ, Miller WL: P450c17 mutations $\mathrm{R} 347 \mathrm{H}$ and $\mathrm{R} 358 \mathrm{Q}$ selectively disrupt 17,20-lyase activity by disrupting interactions with P450 oxidoreductase and cytochrome $b_{5}$. Mol Endocrinol 1999;13:167175. 
-11 Guengerich FP, Johnson WW: Kinetics of ferric cytochrome $\mathrm{P} 450$ reduction by NADPH-cytochrome P450 reductase: rapid reduction in the absence of substrate and variations among cytochrome $\mathrm{P} 450$ systems. Biochemistry 1997;36:14741-14750.

12 Yanagibashi K, Hall PF: Role of electron transport in the regulation of the lyase activity of C21 side-chain cleavage P-450 from porcine adrenal and testicular microsomes. J Biol Chem 1986;261:8429-8433.

$\checkmark 13$ Lin D, Black SM, Nagahama Y, Miller WL: Steroid $17 \alpha$-hydroxylase and 17,20-lyase activities of P450c17: contributions of serine $\mathrm{e}^{106}$ and P450 reductase. Endocrinology 1993; 132:2498-2506.

14 Peterson RE, Imperato-McGinley J, Gautier T, Shackleton C: Male pseudohermaphroditism due to multiple defects in steroid-biosynthetic microsomal mixed-function oxidases. A new variant of congenital adrenal hyperplasia. N Engl J Med 1985;313:11821191.

-15 Malunowicz E, Romer TE, Szarras-Czapnik M, Mielniczuk Z, Gajewska D: Combined deficiency of $17 \alpha$-hydroxylase and 21-hydroxylase in an 8 years old girl. Endokrynol Pol 1987;38:117-124.

-16 Augarten A, Pariente C, Gazit E, Chayen R, Goldfarb H, Sack J: Ambiguous genitalia due to partial activity of cytochromes $\mathrm{P} 450 \mathrm{c} 17$ and P450c21. J Steroid Biochem Mol Biol 1992;41:37-41.

-17 Leiberman E, Hershkovitz E, Lauber-Biason A, Phillip M, Zachmann M: Subnormal cortisol response to adrenocorticotropin in isolated partial 17,20-lyase deficiency. J Pediatr Endocrinol Metab 1997;10:387-390.

-18 Adachi M, Tachibana K, Asakura Y, Suwa S, Nishimura G: A male patient presenting with major clinical symptoms of glucocorticoid deficiency and skeletal dysplasia, showing a steroid pattern compatible with $17 \alpha$ hydroxylase/17,20-lyase deficiency, but without obvious CYP17 gene mutations. Endocr J 1999;46:285-292.

19 Reardon W, Smith A, Honour JW, Hindmarsh P, Das D, Rumsby G, Nelson I, Malcolm S, Ades L, Sillence D, Kumar D, DeLozier-Blanchet C, McKee S, Kelly T, McKeehan WL, Baraitser M, Winter RM: Evidence for digenic inheritance in some cases of Antley-Bixler syndrome? J Med Genet 2000;37:26-32.

-20 Kelley RI, Kratz LE, Glaser RL, Netzloff ML, Wolf LM, Jabs EW: Abnormal sterol metabolism in a patient with Antley-Bixler syndrome and ambiguous genitalia. Am J Med Genet 2002;110:95-102.

-21 Miller WL: Congenital adrenal hyperplasia. N Engl J Med 1987;317:1413-1415.
22 Otto DM, Henderson CJ, Carrie D, Davey M, Gundersen TE, Blomhoff R, Adams RH, Tickle C, Wolf CR: Identification of novel roles of the cytochrome P450 system in early embryogenesis: effects on vasculogenesis and retinoic acid homeostasis. Mol Cell Biol 2003;23:6103-6116.

23 Shen AL, O'Leary KA, Kasper CB: Association of multiple developmental defects and embryonic lethality with loss of microsomal NADPH-cytochrome P450 oxidoreductase. J Biol Chem 2002;277:6536-6541.

24 Gu J, Weng Y, Zhang QY, Cui H, Behr M, Wu L, Yang W, Zhang L, Ding X: Liver-specific deletion of the NADPH-cytochrome P450 reductase gene: impact on plasma cholesterol homeostasis and the function and regulation of microsomal cytochrome $\mathrm{P} 450$ and heme oxygenase. J Biol Chem 2003;278: 25895-25901.

25 Henderson CJ, Otto DM, Carrie D, Magnuson MA, McLaren AW, Rosewell I, Wolf CR: Inactivation of the hepatic cytochrome P450 system by conditional deletion of hepatic cytochrome P450 reductase. J Biol Chem 2003; 278:13480-13486.

26 Huang N, Pandey AV, Agrawal V, Reardon W, Lapunzina PD, Mowat D, Jabs EW, Van Vliet G, Sack J, Flück CE, Miller WL: Diversity and function of mutations in P450 oxidoreductase in patients with Antley-Bixler syndrome and disordered steroidogenesis. Am J Hum Genet 2005;76:729-749.

27 Fukami M, Horikawa R, Nagai T, Tanaka T, Naiki Y, Sato N, Okuyama T, Nakai H, Soneda S, Tachibana K, Matsuo N, Sato S, Homma K, Nishimura G, Hasegawa T, Ogata T: Cytochrome $\mathrm{P} 450$ oxidoreductase gene mutations and Antley-Bixler syndrome with abnormal genitalia and/or impaired steroidogenesis: molecular and clinical studies in 10 patients. J Clin Endocrinol Metab 2005;90:414-426.

28 Fukami M, Hasegawa T, Horikawa R, Ohashi T, Nishimura G, Homma K, Ogata T: Cytochrome $\mathrm{P} 450$ oxidoreductase deficiency in three patients initially regarded as having 21-hydroxylase deficiency and/or aromatase deficiency: diagnostic value of urine steroid hormone analysis. Pediatr Res 2006;59:276280.

29 Homma K, Hasegawa T, Nagai T, Adachi M, Horikawa R, Fujiwara I, Tajima T, Takeda R, Fukami M, Ogata T: Urine steroid hormone profile analysis in cytochrome $\mathrm{P} 450$ oxidoreductase deficiency: implication for the backdoor pathway to dihydrotestosterone. J Clin Endocrinol Metab 2006;91:2643-2649.

30 Antley R, Bixler D: Trapezoidocephaly, midfacial hypoplasia and cartilage abnormalities with multiple synostoses and skeletal fractures. Birth Defects Orig Artic Ser 1975; 11:397-401.

- 31 DeLozier CD, Antley RM, Williams R, Green N, Heller RM, Bixler D, Engel E: The syndrome of multisynostotic osteodysgenesis with long-bone fractures. Am J Med Genet 1980;7:391-403.
2 Crisponi G, Porcu C, Piu ME: Antley-Bixler syndrome: case report and review of the literature. Clin Dysmorphol 1997;6:61-68.

33 Bottero L, Cinalli G, Labrune P, Lajeunie E, Renier D: Antley-Bixler syndrome. Description of two new cases and a review of the literature. Childs Nerv Syst 1997;13:275-280; discussion 281.

34 Chun K, Siegel-Bartelt J, Chitayat D, Phillips J, Ray PN: FGFR2 mutation associated with clinical manifestations consistent with Antley-Bixler syndrome. Am J Med Genet 1998; 77:219-224.

35 Gorlin RJ: Patient described by Chun et al. may not present Antley-Bixler syndrome. Am J Med Genet 1999;83:64.

36 Gripp KW, Stolle CA, McDonald-McGinn DM, Markowitz RI, Bartlett SP, Katowitz JA, Muenke M, Zackai EH: Phenotype of the fibroblast growth factor receptor 2 Ser351Cys mutation: Pfeiffer syndrome type III. Am J Med Genet 1998;78:356-360.

37 Schinzel A, Savoldelli G, Briner J, Sigg P, Massini C: Antley-Bixler syndrome in sisters: a term newborn and a prenatally diagnosed fetus. Am J Med Genet 1983;14:139147.

38 LeHeup BP, Masutti JP, Droulle P, Tisserand J: The Antley-Bixler syndrome: report of two familial cases with severe renal and anal anomalies. Eur J Pediatr 1995;154:130-133.

39 Feigin E, Udassin R, Seror D, Szold A, Ben Neriah Z, Glick B: Antley-Bixler syndrome and esophageal atresia in a patient with trisomy 21. Clin Genet 1995;47:53-55.

40 Pulleyn LJ, Reardon W, Wilkes D, Rutland P, Jones BM, Hayward R, Hall CM, Brueton L, Chun N, Lammer E, Malcolm S, Winter RM: Spectrum of craniosynostosis phenotypes associated with novel mutations at the fibroblast growth factor receptor 2 locus. Eur J Hum Genet 1996;4:283-291.

41 Schaefer F, Anderson C, Can B, Say B: Novel mutation in the FGFR2 gene at the same codon as the Crouzon syndrome mutations in a severe Pfeiffer syndrome type 2 case. Am J Med Genet 1998;75:252-255.

42 Cohen MM Jr: The new bone biology: pathologic, molecular, and clinical correlates. Am J Med Genet A 2006;140:2646-2706.

43 Muenke M, Schell U, Hehr A, Robin NH, Losken HW, Schinzel A, Pulleyn LJ, Rutland P, Reardon W, Malcolm S, et al: A common mutation in the fibroblast growth factor receptor 1 gene in Pfeiffer syndrome. Nat Genet 1994;8:269-274.

44 Reardon W, Winter RM, Rutland P, Pulleyn LJ, Jones BM, Malcolm S: Mutations in the fibroblast growth factor receptor 2 gene cause Crouzon syndrome. Nat Genet 1994;8: 98-103.

45 Rutland P, Pulleyn LJ, Reardon W, Baraitser M, Hayward R, Jones B, Malcolm S, Winter RM, Oldridge M, Slaney SF, et al: Identical mutations in the FGFR2 gene cause both Pfeiffer and Crouzon syndrome phenotypes. Nat Genet 1995;9:173-176. 
46 Park WJ, Meyers GA, Li X, Theda C, Day D, Oriow SJ, Jones MC, Jabs EW: Novel FGFR2 mutations in Crouzon and Jackson-Weiss syndromes show allelic heterogeneity and phenotypic variability. Hum Mol Genet 1995;4:1229-1233.

-47 Lajeunie E, Ma HW, Bonaventure J, Munnich A, Le Merrer M, Renier D: FGFR2 mutations in Pfeiffer syndrome. Nat Genet 1995; 9:108.

-48 Pursley TJ, Blomquist IK, Abraham J, Andersen HF, Bartley JA: Fluconazole-induced congenital anomalies in three infants. Clin Infect Dis 1996;22:336-340.

-49 Aleck KA, Bartley DL: Multiple malformation syndrome following fluconazole use in pregnancy: report of an additional patient. Am J Med Genet 1997;72:253-256.

-50 Lee BE, Feinberg M, Abraham JJ, Murthy AR: Congenital malformations in an infant born to a woman treated with fluconazole. Pediatr Infect Dis J 1992;11:1062-1064.
1 Shackleton C, Marcos J, Arlt W, Hauffa BP: Prenatal diagnosis of P450 oxidoreductase deficiency (ORD): a disorder causing low pregnancy estriol, maternal and fetal virilization, and the Antley-Bixler syndrome phenotype. Am J Med Genet A 2004;129: 105-112.

52 Gofflot F, Hars C, Illien F, Chevy F, Wolf C, Picard JJ, Roux C: Molecular mechanisms underlying limb anomalies associated with cholesterol deficiency during gestation: implications of Hedgehog signaling. Hum Mol Genet 2003;12:1187-1198.

53 Geller DH, Auchus RJ, Mendonca BB, Miller WL: The genetic and functional basis of isolated 17,20-lyase deficiency. Nat Genet 1997; 17:201-205.

54 Auchus RJ, Miller WL: Molecular modeling of human P450c17 (17 $\alpha$-hydroxylase/17,20lyase): insights into reaction mechanisms and effects of mutations. Mol Endocrinol 1999; 13:1169-1182.

55 Krone N, Dhir V, Ivison HE, Arlt W: Congenital adrenal hyperplasia and $\mathrm{P} 450$ oxidoreductase deficiency. Clin Endocrinol (Oxf) 2007;66:162-172.
6 Auchus RJ: The backdoor pathway to dihydrotestosterone. Trends Endocrinol Metab 2004;15:432-438.

57 Meinhardt U, Mullis PE: The aromatase cytochrome P-450 and its clinical impact. Horm Res 2002;57:145-152.

58 Wilson JD, Auchus RJ, Leihy MW, Guryev OL, Estabrook RW, Osborn SM, Shaw G, Renfree MB: $5 \alpha$-Androstane- $3 \alpha, 17 \beta$-diol is formed in tammar wallaby pouch young testes by a pathway involving $5 \alpha$-pregnane$3 \alpha, 17 \alpha$-diol-20-one as a key intermediate. Endocrinology 2003;144:575-580.

59 Gupta MK, Guryev OL, Auchus RJ: $5 \alpha$-Reduced C21 steroids are substrates for human cytochrome P450c17. Arch Biochem Biophys 2003;418:151-160.

60 Jacobson RL, Dignan PS, Miodovnik M, Siddiqi TA: Antley-Bixler syndrome. J Ultrasound Med 1992;11:161-164.

61 Antonarakis SE: Recommendations for a nomenclature system for human gene mutations. Nomenclature Working Group. Hum Mutat 1998;11:1-3. 